\title{
Erratum to: Transverse dental arch relationship at 9 and 12 years in children with unilateral cleft lip and palate treated with infant orthopedics: a randomized clinical trial (DUTCHCLEFT)
}

\author{
R. L. M. Noverraz ${ }^{1}$ M. A. Disse ${ }^{1}$ - E. M. Ongkosuwito ${ }^{2}$ - A. M. Kuijpers-Jagtman ${ }^{2}$ • \\ C. Prahl ${ }^{1}$
}

Published online: 16 August 2015

(C) Springer-Verlag Berlin Heidelberg 2015

\section{Erratum to: Clinical Oral Investigations \\ DOI 10.1007/s00784-015-1451-2}

The original version of the above article contained a mistake due to incorrect alignment of entries in Tables 11 and 14 during production. The entries are presented correctly below.

The online version of the original article can be found at http://dx.doi.org/ 10.1007/s00784-015-1451-2.

\section{Prahl}

c.prahl@acta.nl

1 Department of Orthodontics, Academic Centre for Dentistry Amsterdam (ACTA), Gustav Mahlerlaan 3004, 1081 LA Amsterdam, The Netherlands

Table 11 Evaluation of the total arch constriction in pairs

\begin{tabular}{|c|c|c|c|c|c|c|}
\hline & \multirow[t]{2}{*}{ Center } & \multirow[t]{2}{*}{ Center } & \multirow[t]{2}{*}{ Mean } & \multicolumn{2}{|c|}{$95 \% \mathrm{CI}$} & \multirow[t]{2}{*}{$P$} \\
\hline & & & & Lower & Upper & \\
\hline \multirow[t]{3}{*}{9 years } & 1 & 2 & 1.63 & -2.09 & 5.34 & 0.842 \\
\hline & 1 & 3 & -1.71 & -5.61 & 2.18 & 0.836 \\
\hline & 2 & 3 & -3.34 & -6.73 & .05 & 0.054 \\
\hline \multirow[t]{3}{*}{12 years } & 1 & 2 & 4.85 & 0.53 & 9.17 & $0.023 *$ \\
\hline & 1 & 3 & -4.39 & -4.02 & 4.95 & 1.000 \\
\hline & 2 & 3 & 0.47 & -8.33 & -0.44 & $0.025 *$ \\
\hline
\end{tabular}

Mean mean total arch constriction score (points), 95\% CI $95 \%$ confidence interval of the difference

${ }^{*} p<0.05$

Table 14 Evaluation of age of hard palate closure with alveolar bone grafting in pairs

\begin{tabular}{llllrl}
\hline \multirow{2}{*}{ Center } & Center & Mean diff & \multicolumn{2}{l}{$95 \% \mathrm{CI}$} & \multirow{2}{*}{$P$} \\
\cline { 3 - 5 } & & & Lower & Upper & \\
\hline 1 & 2 & -1.55 & -2.43 & 0.68 & $0.000^{* * * *}$ \\
1 & 3 & -0.99 & -1.88 & -0.11 & 0.023 \\
2 & 3 & 0.56 & -0.20 & 1.32 & 0.218 \\
\hline
\end{tabular}

2 Department of Orthodontics and Craniofacal Biology and Cleft Palate Craniofacial Centre, Radboud University Medical Centre, Nijmegen, The Netherlands

Mean diff mean difference in age of hard palate closure with alveolar bone grafting (years), $95 \%$ CI $95 \%$ confidence interval of the difference $* * * p<0.001$ 